\title{
PARA ALÉM DO MURO DA ESCOLA: A ARTE COMO LUGAR DE INTERAÇÕES E DESCOBERTAS
}

\author{
Valéria Maria Chaves de Figueiredo ${ }^{1}$ \\ Izabel Cristina Soares Leal ${ }^{2}$ \\ Mírian Ribeiro Machado ${ }^{3}$
}

\begin{abstract}
Resumo: Este artigo trata de um relato de experiência da parceria vivenciada entre os discentes do estágio curricular obrigatório em dança da Faculdade de Educação Física e Dança da Universidade Federal de Goiás e a Escola Municipal Professora Maria Nosídia Palmeira das Neves. Essas experiências estão vinculadas a projetos, pautados nas perspectivas de escolas criativas, onde o conhecimento não se limita apenas às paredes da sala de aula. Ele vai além, ultrapassa os muros da escola. E isso acontece por meio de práticas inovadoras em prol de um ensino de qualidade. Ressalta a importância da promoçáo da criatividade no âmbito escolar. Nesse sentido, as relaçóes entre escola e práticas criativas e inovadoras não podem ser concebidas como dois polos independentes, mas sim como universos entrelaçados, como uma teia tecida no cotidiano com fios e nós profundamente articulados. Assim, construímos uma escola criativa trilhando caminhos diversos de aprendizagens, de sentidos e significados.
\end{abstract}

Palavras-Chave: Dança. Escola. Processos de Criação. Interação.

\section{BEYOND THE SCHOOL WALLS: ART AS A PLACE OF INTERACTIONS AND DISCOVERIES.}

\begin{abstract}
This article is a report of an experience of the partnership experienced by the students as part of their compulsory curricular internship, which is the required internship of dance's course in the Faculty of Physical Education and Dance of the Federal University of Goiás and the Public School Professor Maria Nosídia Palmeiras das Neves. These experiences are linked to projects, based on the
\end{abstract}

1 Professora Associada da UFG. Doutora em Educação. Coordenadora do estágio da licenciatura em Dança da FEFD/UFG.

2 Professora da Secretaria Municipal de Educação. Mestre em Educação do ensino superior. Diretora da Escola Municipal Professora Maria Nosídia Palmeira das Neves.

3 Professora de dança da Escola Municipal Professora Maria Nosídia Palmeira das Neves. Especialista em ginástica de academia e em fisiologia, aptidão física e saúde. 
perspectives of creative schools, where knowledge is not limited only to the walls of the classroom. It goes beyond, transcends the walls of the school. And this is done through innovative practices for quality teaching. It emphasizes the value of promoting creativity in school, as well. In this sense, the relationships between school and creative and innovative practices cannot be conceived between two independent poles, but as connected universes, like a web woven in daily life with threads and deeply articulated nodes. This way, we've built a creative school by treading diverse paths of learning, senses and meanings.

Keywords: Dance. School. Processes of creation. Interaction.

\section{CAMINHOS PARA REFLEXÃO}

A função social da escola, entre tantas outras, é a de promover aos educandos uma aprendizagem cidadã e transformadora. Esse espaço de experimentos, de vivências e de construção do conhecimento tem como objetivo a educação integral dos sujeitos para que estes possam intervir no mundo que o cerca e se responsabilizar por suas ações e atitudes. Segundo Freire (1980), o homem é um ser histórico, social, sujeito de sua própria existência, "capaz de ação transformadora consciente, ou seja, é capaz de agir intencionalmente (e não apenas instintivamente ou por reflexo condicionado) em busca de uma mudança no ambiente que o favoreça" (CORTELLA, 2008, p. 36, grifo do autor).

Pode-se afirmar que a presença da arte nas discussões da educação ainda é restrita frente ao enorme potencial e diversidade da área e o lugar da arte na escola, em nossa região, se dá via uma multiplicidade de formas e espaços. A arte ainda é tida na escola como lugar apenas de lazer ou de recreação, sabe-se que são poucas escolas onde a dança é disciplina regular.

Historicamente, nas últimas décadas, a arte na escola vem conquistando política e formalmente seu lugar por direito, favorecendo aos educadores um universo novo de possibilidades e muitos desafios a serem trabalhados. Não pode se pensar mais em arte como técnicas mecanizadas e/ou reprodutivistas, mas, como pensar em propostas artísticas e educativas que sejam realmente transformadoras? Esse é o caminho? A chegada da arte na escola e a institucionalização dos cursos de formação superior em música, dança, teatro e artes visuais trouxeram novas possibilidades e novos campos de atuação também, alargando os horizontes da prática docente.

Assim, participar e debater tornou-se urgente para esse campo, assim como sair das zonas de conforto e ir à procura, por um lado de reconhecimento e por outro de se envolver politicamente e conscientemente com a sociedade. Consolidamos assim a área como um lugar de saber humano e formativo da sociedade. 
A ideia de uma abordagem educativa em arte foi bastante estudada por teóricos como John Dewey ${ }^{4}$, Hebert Read ${ }^{5}$, Viktor Lowenfeld ${ }^{6}$ e Elliot Einser ${ }^{7}$. A partir do século XX esses estudos foram importantes para se compreender, historicamente, a constituição do campo até então denominado: arte-educação. $\mathrm{O}$ que se verifica, portanto é a ampliação da presença e da relevância do ensino de arte para a escola, deixando de ser práticas meramente técnicas, e se constituindo como fundamental para a formação humana. De acordo com Osinski (2001), o século XX descobre a criança como ser autônomo e valoriza a criatividade e a individualidade. Mas o flagrante descompasso entre os estudos realizados cientificamente e o ensino vigente, marca novamente a necessidade de surgimento de outras investigações que deem conta de uma educação mais criativa, transformadora, crítica e que se rebele contra um sistema unilateral de mera transmissão de conhecimentos.

Percebe-se assim que dos primeiros movimentos de educação artística na educação formal no início do século XIX, até as primeiras ideias da arte-educação a partir dos anos 70 configuram-se importantes batalhas e vitórias para que arte na escola desempenhe de fato papel de formadora e integrada aos processos pedagógicos. De acordo com Ferraz e Fusari (2010, pg. 19), nos últimos anos o movimento da arte-educação esteve preocupado com a educação escolar, observando e contribuindo para efetivar a presença da arte na lei de diretrizes e bases da educação. Vale lembrar que a LDB n. 9394 de 1996 estabeleceu a obrigatoriedade do ensino da arte na educação básica modificando finalmente a relação da arte com a escola pública. O movimento de arte-educação, de fato, se iniciou fora da escola, mas esteve ancorado nas ideias da "escola nova" e da "educação através da arte" . Ferraz e Fusari (2010) apontaram que, enquanto o movimento de educação artística esteve preocupado apenas com a expressividade individual e as técnicas,

4 John Dewey (1859-1952), filósofo norte-americano que influenciou educadores de várias partes do mundo. Ver: BARBOSA, Ana Mae. John Dewey e o ensino da arte no Brasil. São Paulo: Cortez, 2002.

5 Hebert Read (1893-1968), poeta, crítico de arte e militante anarquista. Ver: BARBOSA, Ana Mae. John Dewey e o ensino da arte no Brasil. São Paulo: Cortez, 2002.

6 Viktor Lowenfeld (1903-1960), austríaco, professor de educação artística na Universidade estadual da Pensilvânia. Suas idéias influenciaram educadores de arte nos Estados Unidos do pós-guerra. Ver: LOWENFELD, Victor \& BRITTAIN, W. Lambert. O desenvolvimento da capacidade criadora. São Paulo: Mestre Jou, 1977.

7 Elliot Einser (1933-2014), foi professor de Arte e Educação na Stanford Graduate School of Education e uma das principais mentes acadêmicas dos Estados Unidos. Ver: BARBOSA, Ana Mae. Leituras no subsolo. São Paulo, Cortez: 1999.

8 John Dewey inspirou o movimento da Escola Nova no Brasil liderado por Anísio Teixeira ao colocar a atividade prática e a democracia como importantes ingredientes da educação. Ver: BARBOSA, Ana Mae. John Dewey e o ensino da arte no Brasil. São Paulo: Cortez, 2002.

9 Essas ideias estão baseadas nos estudos de Herbert Read, especialmente de sua obra sobre a "Educação Através da Arte". Ver: READ, H. A educação pela arte. São Paulo: Martins Fontes, 1982. 
uma necessidade de conhecimentos mais aprofundados de arte se formava no entorno, o movimento de arte-educação buscou, portanto, novas metodologias de ensino, revalorizou o professor e sua área de conhecimento e redimensionou seu trabalho na escola, incluindo a importância da sua ação política e sua atuação profissional na sociedade. Mas quando pesquisamos a escola, quando vivenciamos a escola hoje, vemos que velhos problemas permanecem, a arte ainda representa lugar das atividades meramente recreativas, das festividades furtivas e da produção artística como um lugar de divertimento e que não inclui uma ação educativa.

Buscar compreender a arte no âmbito da escola implica em um exercício de refletir, de se repensar sempre, de saber voltar atrás e consciente de si mesmo fazer tentativas de ampliar as leituras do mundo, na perspectiva da humanização e da compreensão das realidades.

"Refletir" vem do verbo "reflectere" que significa voltar atrás. É um repensar, um pensamento em segundo grau. Um pensamento consciente de si mesmo, capaz de verificar o grau de adequação que mantém com os mesmos dados objetivos da realidade. (SAVIANI, 1989, p. 23). Existem princípios importantes que norteiam o ambiente educacional. Repensar sobre a constituição dos campos de conhecimento e suas relações com ambiente escolar é necessário. Buscamos compreender alguns processos de mediação que se dá através da arte na escola, e como este é um processo complexo, pois envolverá a subjetividade humana, noções de criatividade, de expressividade e comunicação, de desenvolvimento do estético, tanto em questões individuais quanto coletivas.

\section{O PROCESSO DA ARTE É UMA AVENTURA}

Somos pobres de histórias surpreendentes. A razão é que os fatos já nos chegam acompanhados de explicações.

(Walter Benjamin.)

Nessa perspectiva de educação, a escola abre caminhos para que seus sujeitos possam trilhá-los como agentes ativos, capazes de provocar mudança. Essas mudanças acontecem quando a escola, como mobilizadora do saber, cria condições de aprendizagem para que o aluno explore e construa conhecimentos necessários para a vida em sociedade. A Escola Municipal de Tempo Integral Profa. Maria Nosídia Palmeira das Neves tem como princípio educativo o trabalho pedagógico de ação-reflexão-ação com foco na aprendizagem de todos os alunos. Acreditamos que por ser uma realidade de tempo escolar estendido, esse espaço deve propiciar ao aluno maior aproveitamento pedagógico do tempo de modo a extrapolar o conhecimento sistematizado. Essa Unidade de Ensino atende um grupo de aproximadamente trezentos alunos e com poder socioeconômico baixo. A faixa etária dos discentes vai dos seis aos onze anos, compreendendo toda a primeira fase do Ensino Fundamental. A escola oferece uma educação em tempo integral e inclusiva, localizando-se numa região de periferia da cidade. A comunidade local é 
carente de atividades culturais, recreativas e a escola se torna um espaço propício para essas vivências.

Vislumbramos um trabalhado na perspectiva de uma educação transformadora, sendo assim, o fazer pedagógico deve perpassar por todos os espaços da instituição escolar valorizando a mediação e a articulação das ações educativas para que a aprendizagem integral e significativa aconteça para todos. Ter uma visão global desse espaço propicia um olhar diferenciado para cada situação de aprendizagem. Com isso, é possível detectar as necessidades existentes, os pontos de atenção para intervenções precisas a fim de garantir uma educação de qualidade que vai além dos muros da escola.

A nossa ideia era aventurar-nos em espaços tradicionalmente difíceis para arte, o desafio era não empobrecer a linguagem, não didatizar para caber dentro da escola. Por isso, a escolha pelas possibilidades de interlocução entre as artes da dança, do teatro, da música, das artes visuais abrindo frentes de experiências para $o$ lirismo, para poética, para percepção de diferentes realidades e para uma dramaturgia afetiva, abrindo caminhos para a temporalidade e a atemporalidade. Ficou evidente nas avaliações realizadas em debates com equipe e coletivos da universidade e da escola, que os projetos propiciaram arte com qualidade, ampliando as possibilidades da educação estética e da transdisciplinaridade.

A transdisciplinaridade caracteriza-se por ser uma pulsão religadora, por buscar pensar complexo, multidimensional, multirreferencial, articulando razão, emoção, corporeidade e atitude transformadora, trabalhando assim com uma razão sensível e uma práxis complexa e transdisciplinar (SUANNO, 2013. P. 53).

A ideia de projetos interartísticos que valorizassem as relações com a família e com a comunidade foi fundamental no processo de dar novos significados para a escola. Acreditamos em ações artístico-pedagógicas que fazem com que a arte seja de fato parte do processo formador das pessoas. Ao adentrar os muros das escolas com os espetáculos, percebeu-se que o contexto sócio-educativo não é nada distante do fazer criativo e do apreciar artístico. Percebe-se a importância de incentivos por diversas ordens, para que sejam realizadas ações que favoreça um ambiente rico de trocas, parcerias e intervenções artístico-didático-pedagógicas, dentro do processo de ensino-aprendizagem, refletindo sobre o lugar da formação humana e seus múltiplos aspectos.

Portanto, falar de princípios epistemológicos das áreas de conhecimentos presentes no ambiente educacional e sobre o ensino e a aprendizagem desses saberes na escola é abordar o tema a partir de infinitas e complexas possibilidades. Estamos tratando de questões intrinsicamente imbricadas na constituição do conhecimento humano e em diferentes dimensões e práticas, sejam elas artísticas, filosóficas, sociais ou pedagógicas. Refletir sobre a constituição do campo de conhecimentos denominado Arte é falar também de características identificatórias relacionadas aos saberes científicos, culturais, sociais e principalmente artísticos. 
E quando se fala em Arte, logo vem a nossa mente a ideia de que estamos tratando de um conteúdo objetivado eminentemente no fazer artístico, ou seja, apenas na ideia de uma prática e de técnicas que produzem objetos de arte. Se na escola ela se configurou como uma atividade de conteúdos eminentemente práticos, muitas vezes voltados para formar comportamentos e/ou treinar hábitos supostamente adequados aos valores conservadores da sociedade, no campo acadêmico e no campo profissional o seu amadurecimento é crítico, reflexivo, transformador e busca olhares múltiplos e investigativos. Fica sempre a dúvida então, por que a escola trata de diminuir ou destituir o potencial da Arte? Como aproximar a saberes acadêmicos das práticas realizadas nas escolas? Hoje, mais do que em outro momento, sabe-se que os saberes constitutivos da escola provêm/ possuem/integram às dimensões históricas, culturais e sociais e que na própria seleção dos conhecimentos a serem ensinados perpassam sim interesses, conflitos e áreas como a Arte ainda estão em busca de legitimidade e se deparam com inúmeras e diferentes disputas de tempos, espaços e poder.

$\mathrm{Na}$ escola, experimentamos caminhos diversos na constituição destas triangulações muitas vezes conflituosas, entre escola e comunidade, família e escola e arte e escola. Nos fez chegar a questões e escolhas fundamentais e que foram fortalecidas no fazer coletivo, escolhas epistemológicas, que norteiam os projetos a serem desenvolvidos, tais como: o não apagamento das diferenças; a valorização das singularidades que emergem junto com as pluralidades; uma busca constante por encontrar vários modos de ensinar e se aprender; distender e rever sempre as dicotomias entre prática e teoria; não se submeter ou se render ao empobrecimento e ao didatismo dos conteúdos e acreditar na valiosa percepção de circularidade e aberturas para as áreas disciplinares, bem como, aquelas não disciplinares, priorizando a ideia de não neutralidade ou de apenas transmissão de conhecimento instrumental e unilateral.

A formação deste aluno crítico, criativo, consciente, cidadão, participativo, sujeito, são nossa prioridade e deve confrontar-se com a ideia de um professor alienado, passivo, ocioso, despolitizado e tecnicista. Portanto, a formação continuada também é lugar essencial nos projetos na perspectiva de uma escola criativa, coletiva e integrada à comunidade. Sabe-se que fenômeno humano é de fato um lugar complexo, plural e multidimensional e o "ofício de mestre", é certo que enfrenta as tensões e os muitos conflitos do mundo e da escola e não há como fugir deles, mas, como se referiu Arroyo (2000, p. 83), nossa docência será sempre uma humana docência. Um lugar de humanização.

Para além das estruturas, por vezes, rígidas das disciplinas e grades horárias, a Arte pode adentrar a escola não apenas preocupada com o processo de ensinoaprendizagem, mas com a formação humana daqueles que fazem da escola outro lócus de conhecimento, interação, percepção e sensibilidades. Dentro deste contexto, os projetos de arte da escola não somente trazem na sua realização uma preocupação didático-pedagógica linear ou conteudista, mas principalmente espaço para se ampliar o desenvolvimento estético. Segundo Rodrigues (2008) o desenvolvimento estético é um processo sofisticado no qual as ideias se manifestam 
não de forma única e linear. Victor Lowenfeld (1977, p. 369) já apontava que o desenvolvimento estético não estaria separado do desenvolvimento da capacidade criadora e que as crianças estão em diferentes níveis de desenvolvimento e o professor deve selecionar obras que tenham significado para eles.

Assim, é preciso conhecer, identificar o pensamento estético dos alunos e promover atividades, ações e oportunidades que lhes permitam construir novas formas de ver, conhecer e experimentar a arte. Não apenas ter contato, mas ter experiências significativas de sujeito que cria, de autor de sua história, de corpocriante como referiu Dittrich (2010), um corpo integrador de várias dimensões humanas e que também aprende a se auto-organizar.

Nossas escolhas se pautam na perspectiva de buscar inovações didáticasmetodológicas. Suanno (2015) aponta para questões significativas presentes nas inovações didáticas e que se misturam aos conceitos de arte que acreditamos importantes para a formação humana como: fazer emergir o conhecimento sinestésico, perceptivo, sensorial; conhecer signos e significados visíveis e invisíveis; trazer outras noções de tempo e espaço, desenvolver a percepção estética e suas potencialidades, propor transgressões para o sentir, o pensar e o fazer, valorizar as múltiplas realidades e formas de conhecimento, propor fazeres transdisciplinares e práticas emancipatórias, reconhecer a multiplicidade de vozes e olhares, valorizar o comprometimento com o mundo presente e os problemas da atualidade, entre outros. Para Suanno (2015) as inovações didático-pedagógicas-formativas emergem como algo inédito-viável, ou seja, pela disponibilidade de mover-se em outra direção, construindo o inédito, no viável e na possibilidade.

Para os projetos de arte na escola, são deflagradas várias experiências de corporeidades e que se colocam em ação, em direção ao fazer artístico como fonte de conhecimento e vida, ou seja, aquilo que não se aprende somente na lousa, mas no corpo que faz a arte, quer seja na forma de espectador, quer seja como intérprete-criador. Esses múltiplos corpos são requeridos como fonte de alimentação de um fazer artístico qual permite intercâmbios lúdicos e realistas ao mesmo tempo, pois as histórias cantadas, dançadas e teatralizadas trazem em seu bojo as relações humanas e que tecem a vida para além dos muros escolares. Às crianças são convidadas a serem sujeito, autoras, produtoras de afetos, inventoras e que se colocam no âmbito de descobrir novas relações com os outros, consigo e com meio ambiente.

Apresentar os espetáculos que compõem o projeto da escola a cada ano, permite uma interação que vislumbra não somente o aspecto racional e nem, tão pouco, o emocional, mas o racional/emocional que toma forma nas interações humanas, nas relações artista e espectador, nos atuantes que são ao mesmo tempo os artistas e o público, solicitando outras vias de interações sinestésicas, emocionais e racionais que vão compor um quadro de afetações que passam pelas cenas dos espetáculos, mas também, pelas interações humanas e que fazem da Arte um ambiente potente, fértil, múltiplo, que reforma o pensamento, que dá novas formas e finalidades para as relações humanas e que irão compor um quadro socioafetivo 
de aproximações da obra artística, do cotidiano da escola e da vida de cada participante. Como referiu Gadotti,

A que a educação, para ser transformadora, emancipadora, precisa estar centrada na vida, ao contrário da educação neoliberal que está centrada na competividade sem solidariedade. Para ser emancipadora a educação precisa considerar as pessoas, suas culturas, respeitar o modo de vida das pessoas, sua identidade. O ser humano é "incompleto e inacabado" como diz Paulo Freire, em formação permanente (GADOTTI 2003, p. 73).

Assim, identificamos que as práticas artísticas na escola, desenvolvidas na escola, para além da sala de aula, promove processos complexos cognitivos e socializadores. O prazer estético gestado pela apreciação de espetáculos ou a participação neles, alimenta a integração da escola, professores, funcionários, família e comunidade. Isto nos permite supor que a arte na escola constitui espectro mais amplo de ação educativa e criativa, e que é promotora de relações humanas emancipadoras, críticas e solidárias.

\section{A POSSIBILIDADE DE OLHARES DIVERSOS}

Os primeiros contatos com a escola ocorreu através de reunião com os profissionais da instituição (agentes educativos, docentes, coordenadores e gestores), professores colaboradores e os bolsistas do Programa institucional de bolsas de iniciação a docência (Subprojeto de Educação Física da Universidade Católica de Goiás e Música da Universidade Federal de Goiás), estagiários da Universidade Federal de Goiás do curso de Dança e de Música, com o objetivo de conhecer a realidade da escola em diferentes aspectos: gestão, estrutura física, forma de organização, recursos materiais, visão de educação escolar, entre outros.

Após este diagnóstico, realizamos estudos referentes ao tema no qual destacamos alguns autores: Libâneo, Arroyo, Limonta, Santos, Freire, Cortella e outros. $\mathrm{Na}$ oportunidade, efetuamos análise mais aprofundada do Projeto Político Pedagógico (PPP da escola), onde percebemos que a desestrutura nos lares das crianças, ou melhor, familiar, acarretava também a baixa autoestima e a carência emocional, prejudicando ainda mais o desempenho escolar, sendo assim, o pouco envolvimento da família na escola ainda é uma realidade nas instituições de ensino, em especial públicas.

A Escola Professora Maria Nosídia fazia parte desta realidade, com isso, o desenvolvimento das ações pedagógicas que amenizassem esse problema era essencial para o desempenho dos alunos, para o envolvimento íntegro e valorizado do corpo docente e funcionários, para que a comunidade reavaliasse o papel da escola na vida de todos. Ao perceber a complexidade do problema, sentimos a necessidade urgente de reverter esse quadro em prol do bem-estar de toda a comunidade escolar. Trazer a família para dentro da escola constituía o grande desafio e o principal objetivo. Mas como fazer isso?

Então, concentramos nossos esforços em ações que despertassem o interesse da família pela escola. Inúmeras atividades foram planejadas pensando na interação 
família-escola. O objetivo central foi fazer com que as ações pedagógicas propostas na Escola Municipal Professora Maria Nosídia ultrapassassem os muros da escola e chegassem a cada família e a comunidade circunvizinha a fim de promover uma aprendizagem significativa para todos. Desta forma, instigamos a equipe em envolverem-se neste projeto através de discussões, reflexões, e elegeu-se a Arte como este lugar de conquista para uma transformação social. Portanto, objetivamos estimular a participação de todos os integrantes da instituição nos projetos e ações da escola, favorecendo a integração curricular e oportunizando aos pibidianos e estagiários a vivência do trabalho em equipe.

Diante da realidade apresentada, sentimos a necessidade de intensificar o envolvimento da família na vida escolar dos filhos para obtermos os melhores resultados no desenvolvimento integral dos alunos. Resolvemos propor um trabalho diferenciado, abrangendo as diversas áreas do conhecimento e as diferentes linguagens artísticas.

Os objetivos dos projetos de arte estão entrelaçados ao projeto pedagógico da escola, dentre eles destaca-se: institucionalizar a escola como disseminadora de conhecimentos, ideias, valores, cultura, de modo a torná-la também um espaço de convivência familiar e social; promover ações cotidianas de experimentos e vivências de modo a estimular atitudes positivas de responsabilidade para com o ambiente escolar; solidificar valores e hábitos que fortaleçam os vínculos familiares, laços de solidariedade humana e de tolerância recíproca, em prol de uma convivência solidária e disseminar o conhecimento das artes: dança, música, teatro, artes visuais, tornando-a parte do processo formativo e educativo.

As atividades foram desenvolvidas em diferentes etapas, descritas abaixo:

Primeira etapa - Diagnóstico da realidade escolar e reflexão das possibilidades da escola como mobilizadora do conbecimento. A ação inicial girou em torno da motivação de toda a equipe de profissionais desta instituição que se mostrava desanimada com a ausência da família. Reverter esse quadro extremamente complexo não seria uma tarefa fácil. No entanto, acreditamos na possibilidade de mudança.

Segunda etapa - Mediação e articulação do faz̧er pedagógico. Como forma de estimular esta integração, organizamos momentos de culminância de diferentes projetos da escola. Na perspectiva do trabalho de integração curricular, promovemos o acesso da comunidade escolar aos ensaios para assistir, prestigiar, participar desses momentos de interação das diferentes linguagens culturais: a dança, a música, o teatro, a música, a contação de histórias, bem como o reconhecimento desta como parte integrante das ações cotidianas de aprendizagem.

Quarta etapa: A escola como disseminadora de bens culturais. Tendo em mente atitudes positivas como solidificadoras de valores e hábitos de fortalecimento da convivência solidária e da aprendizagem, promovemos ações que objetivassem a dinamização das diversas formas de linguagens na escola. Realizamos as seguintes atividades, todas abertas à comunidade escolar: Parada literária, Minha família é show, Sarau literário (criação e recriação de histórias e poesias a partir da temática inspirada na obra O Pequeno Príncipe de Saint Exupéry), entre outras. Assim, enfatizamos 
a importância de valores como: amizade, respeito, solidariedade, valorização da diversidade, ética, solidariedade e cidadania. Realizamos também a produção de jogos com regras de convivência e combinados, produção de programas de rádio, de expressão corporal, pequenas peças teatrais. Por meio dessas ações, os pais começaram a perceber a escola como um espaço de oportunidades de conhecimento, de cultura, de convivência, de lazer. Isso despertou o desejo de fazer parte desse contexto. A cada apresentação realizada na escola o número de pais foi aumentando consideravelmente, o que interferiu diretamente na motivação de todos e na aprendizagem dos alunos. Essa participação efetiva da família fez com que a escola se movimentasse ainda mais, gerando a necessidade de romper barreiras.

Quinta etapa: Produção do espetáculo Felicidade - Com base no texto O Pequeno Príncipe e de produções realizadas por professores e alunos, nasceu o espetáculo Felicidade. Essa ação contou com a participação de todos. A ideia surgiu em uma reunião pedagógica após avaliação dos trabalhos anteriormente realizados. Em sala de aula, os professores nas suas disciplinas elaboraram com os alunos o roteiro do que deveria constar na peça, segundo os temas já estudados. Com o roteiro pronto, passamos para a segunda fase da produção: a seleção dos atores, das músicas, e montagem das coreografias. Várias frentes de trabalhos foram abertas e responsabilidades foram delegadas, tais como: produção de figurino, de cenário, de divulgação, de organização do tempo de ensaios, dos patrocinadores, entre outros. Participamos de um Workshop com profissionais da Secretaria Municipal de Educação. Estagiários da Faculdade de Música e Dança da Universidade Federal de Goiás, bolsistas do PIBID do curso de licenciatura de Educação Física da PUCGO, um artista local, juntamente com a professora de música e de dança. Os alunos de nossa escola escolheram a trilha sonora composta por um repertório de músicas variadas de acordo com a temática. Além disso, eles vivenciaram a prática de cantar em conjunto e tocar instrumentos musicais de percussão e corda. Foi utilizado o repertório musical dos seguintes artistas: Pink Floyd, Luiz Gonzaga, Marcelo Jeneci, Led Zeppellin, Cazuza, Falamansa, Milton Nascimento e adaptação da música Money Money de Liza Minelli. Vale aqui ressaltar que as fotos apresentadas possuem autorização expressa dos pais. A escola solicita autorização de uso de imagem no ato da matrícula qual elucida que o uso diz respeito exclusivamente ao contexto escolar. 
Imagem 1: Espetáculo Felicidade. Teatro da Emac/UFG.

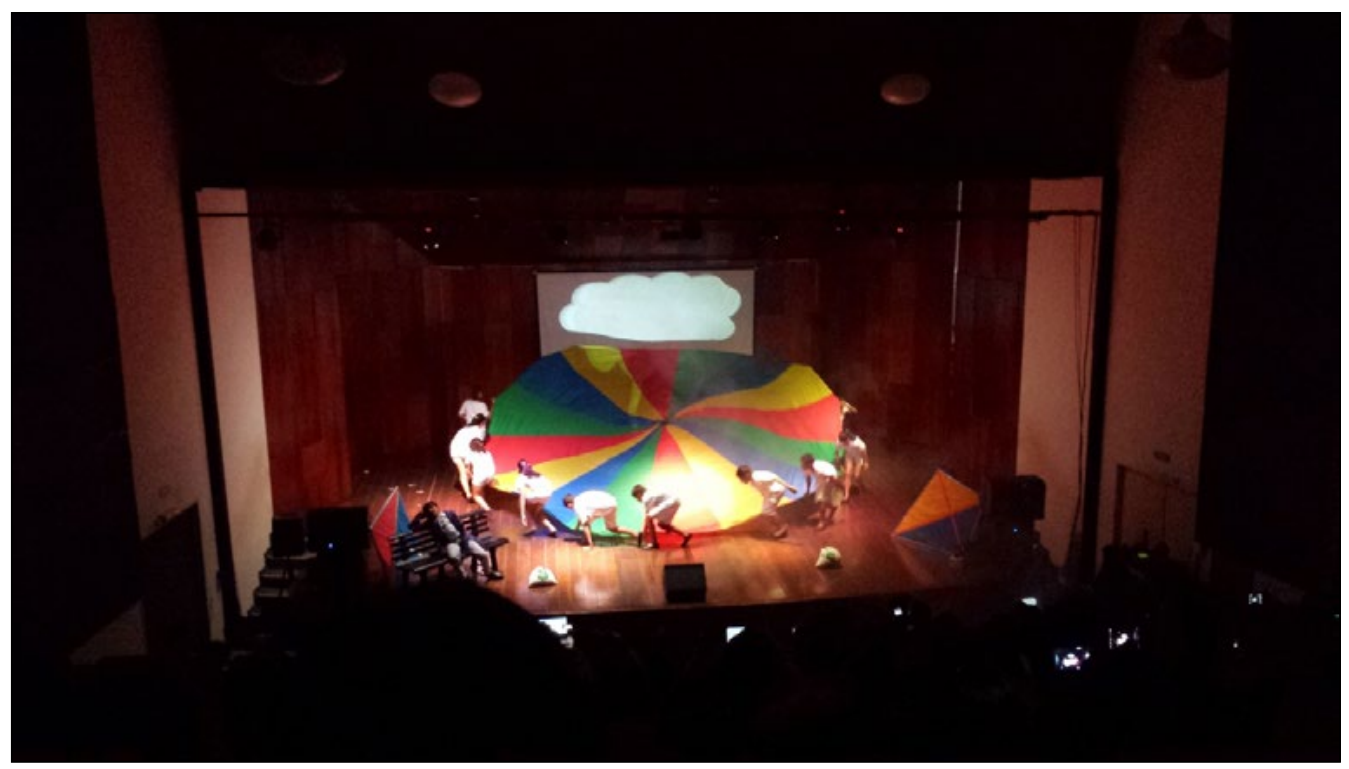

Foto: arquivo da escola.

Imagem 2: Espetáculo Felicidade. Teatro da Emac/UFG.

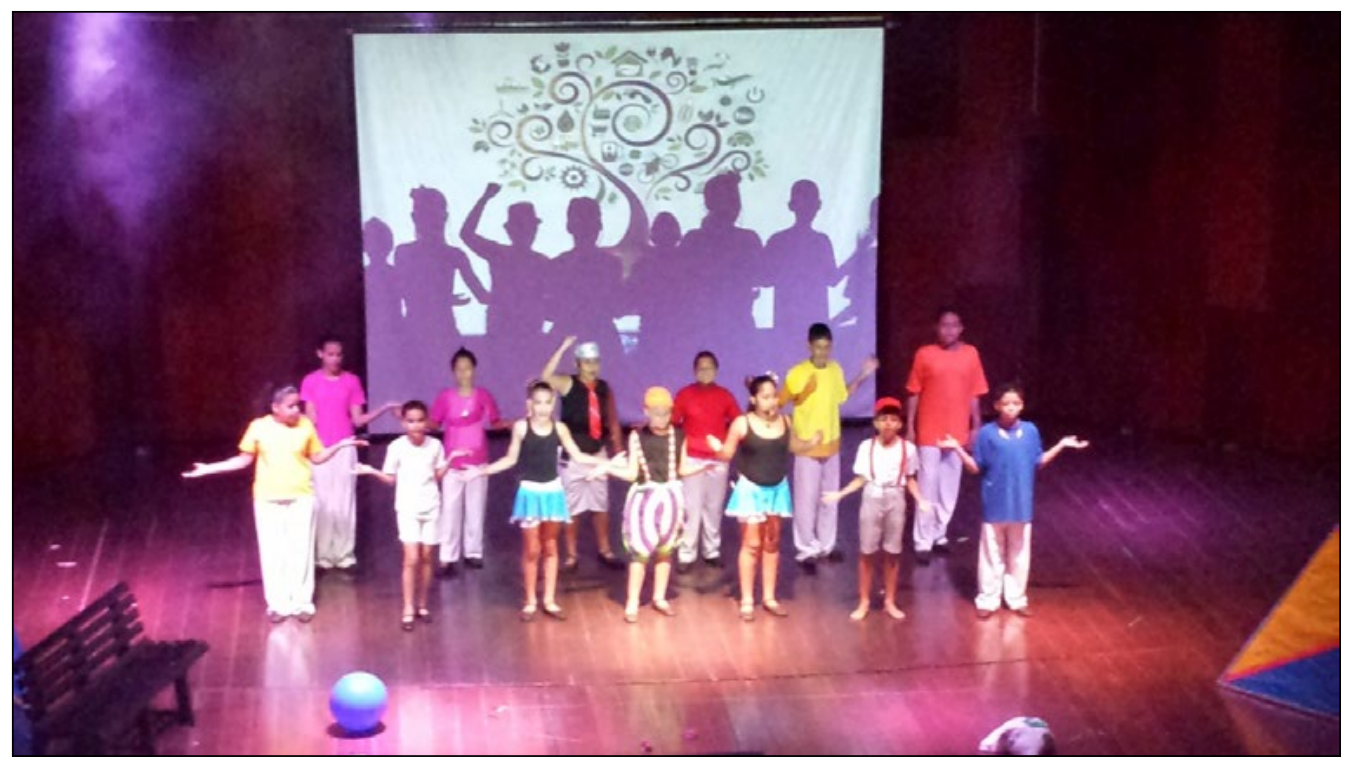

Foto: arquivo da escola.

Também entendemos que a leitura é um dos meios pelo quais se obtém conhecimento das mais diversas áreas facilitando, então, a argumentação e o 
vocabulário para a produção de um texto oral e também escrito. A escola tem grande parcela de responsabilidade no que diz respeito ao incentivo à leitura. Acreditamos que há necessidade de o ser humano adquirir ao longo de sua vida uma boa bagagem de leitura, pois além de obter conhecimento, desenvolve um potencial crítico para o questionamento, para a reflexão e, com isso, saber mais e expor opiniões sem medo, e acima de tudo interpretar o mundo. Nessa perspectiva, a escola prioriza os projetos de leitura com o objetivo de possibilitar aos alunos o despertar de sua criatividade e reflexão crítica sobre seu próprio contexto de vivência. Para suscitar o desejo e garantir o prazer da leitura, possibilitamos aos nossos alunos o direito de escolher o que queriam ler, reler e ler em qualquer espaço da escola. Na perspectiva do letramento, a escola desenvolve vários projetos de leitura e escrita, envolvendo a arte da dança, música e teatro, tendo em vista a experiência da expressividade, da criatividade, da comunicação, a capacidade de solucionar conflitos, às relações afetivas.

A arte na escola é um campo híbrido, plural e dialógico. Nos últimos anos os projetos de arte fazem parte da rotina da escola, transformando o ambiente escolar em lugar de convivência, de parcerias, de criatividade, de experiências vividas, de difusão cultural, de consciência de cidadania, de apreciação, de leitura da cultura e suas diversidades, enfim são muitos os caminhos, a ver:

\section{PROJETO DE INVASÃO POÉTICA}

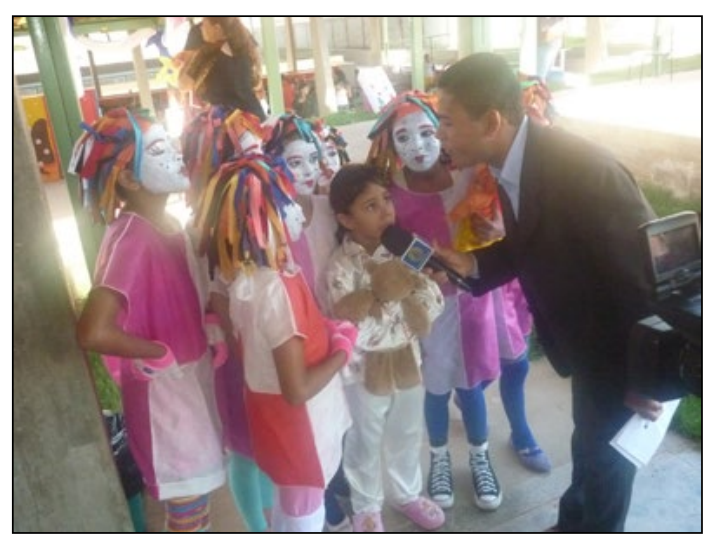




\section{E DO ATELIÊ LITERÁRIO}

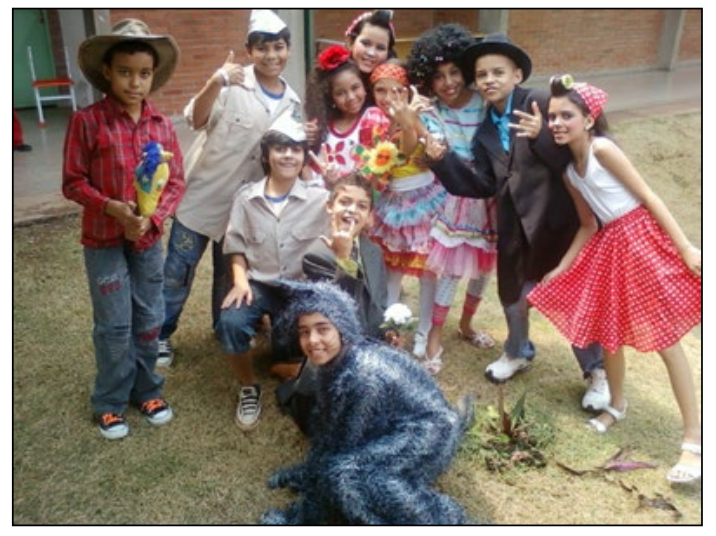

\section{PROJETO MALA DE LEITURA}

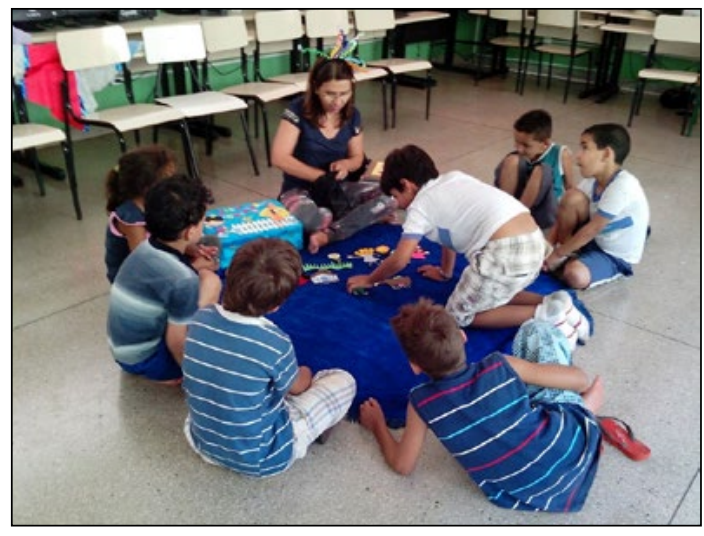

\section{E A PARADA LITERÁRIA}

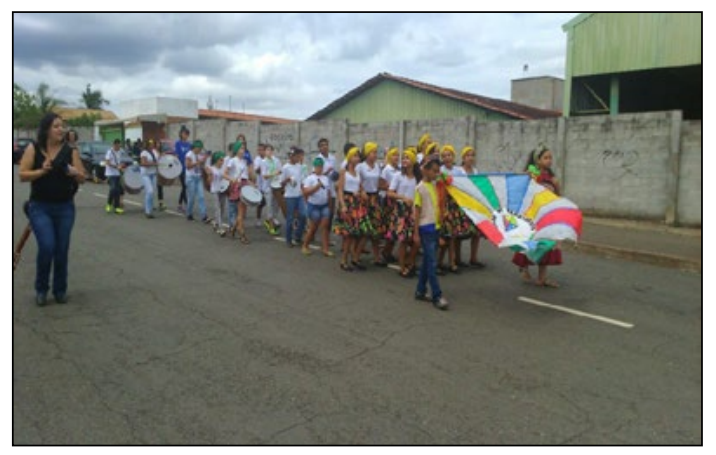




\section{PROJETO SARAU}
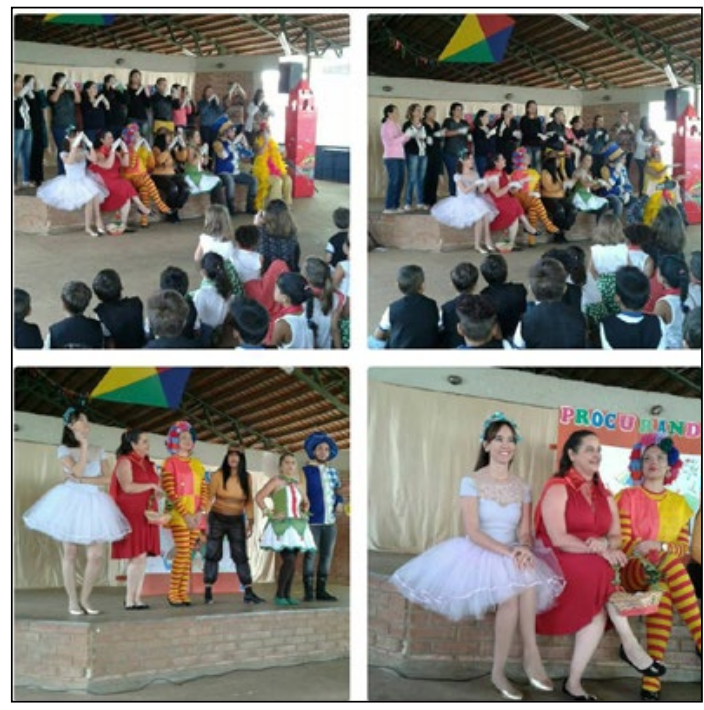

\section{PROJETO DE COMUNICAÇÃO INTERGERACIONAL: A CRIANÇA E O IDOSO}

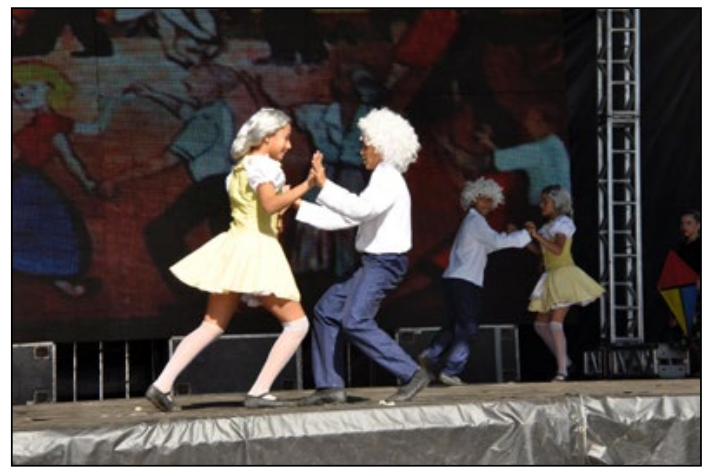

\section{NOSSOS CAMINHOS ESTÁO ABERTOS}

Acreditamos que cada um é responsável por agregar atitudes transdisciplinares, criativas e transformadoras ao espaço que o cerca e a possibilidade de trabalhar as questões referentes à cultura da humanidade, a arte e a ampliação da consciência humana no contexto escolar vem como forma de transformar e compreender o mundo via arte permite não apenas se perceber para aquilo que representa, mas que também expressa sentimentos, fazeres, modos e ideias.

Nesse processo de construção, fica evidente o que apresenta Cortella (2008, p. 36) sobre a importância das ações transformadoras da escola. Com as atividades realizadas, pensamos que os envolvidos nos projetos foram capazes de concretizar "ação transformadora consciente, ou seja, de agir intencionalmente (e não apenas 
instintivamente ou por reflexo condicionado) em busca de uma mudança no ambiente".

O nosso trabalho hoje se volta para elaboração de projetos de arte que estejam ancorados em práxis complexas e transdisciplinares, como referiu Suanno (2015), estar em busca de projetos pautados no desenvolvimento de se melhorar a qualidade educativa e formativa da educação, com criatividade e principalmente com práticas inovadoras. Torre (2008) apresenta outros aspectos importantes para a presença de ações criativas e de inovação para o Projeto Político Pedagógico e que muito nos aproxima do conceito de escola criativa, porém sabendo sempre que é um trabalho em construção, que não está dado, nem acabado, que é um novo processo a cada ano, coletivo, desafiante e que aproxime nossa práxis pedagógica e nossa práxis artística com questões fundantes, a ver:

Liderança estimuladora e criativa- Fomentamos a geração de ideias que não seja algo escondido, mas sim algo valorizado e encorajado, através da mobilização das pessoas para que saibam que suas ideias e suas pequenas sugestões do dia a dia podem, de fato, criar mudanças que geram um ambiente estimulador e transformador.

Professor criativo - $O$ conhecimento não se limita apenas às paredes da sala de aula. Ele está em todos os lugares, por todos os espaços da escola. Professores são verdadeiros agentes na transformação de um ambiente educacional mais acolhedor, mais humano, mais participativo, mais integrado entre alunos, professores e comunidade escolar.

Cultura inovadora- Promovemos aprendizagem inovadora além dos muros da escola, damos voz às crianças, queremos os pais e a comunidade por perto, repassamos responsabilidades aos pequenos e damos importância ao pensar e ao argumentar. Os professores fazem a mediação com os alunos na construção do conhecimento.

Criatividade como valor- Defendemos a criatividade coletiva. Temos como prioridade a manutenção de um ambiente favorável ao desenvolvimento do pensamento criativo.

Espírito Empreendedor- Aguçamos a imaginação e a criatividade e estimulamos sua vontade de realizar sonhos e pôr em prática ideias novas, seja mais forte que as dificuldades encontradas no caminho. Acreditamos que desta forma promovemos o espírito empreendedor de nossos educandos.

Visão transdisciplinar e transformadora, currículo polivalente, metodologia inovadora - Buscamos superar a fragmentação e a descontextualização do conhecimento, ou seja, uma aprendizagem mais conectada à realidade com sentido e significado para o aluno. Sendo assim, a escola tem a incumbência de apresentar aos estudantes novas possibilidades de desenvolver a criatividade, como por meio das variadas expressões artísticas. Artes visuais, música, dança, literatura, intervenções urbanas, entre outros, consideramos ser excelentes formas 
de encorajar os alunos a pensarem além do senso comum e serem mais criativos em diferentes situações o dia a dia.

Valores humanos, sociais e ambientais- Proporcionamos um clima escolar saudável que auxilia na aprendizagem e na formação da identidade dos educandos, tornando-os cientes de suas responsabilidades com o meio ambiente, capazes de desenvolver atitudes de proteção e melhoria junto a ele e para ele. Nesse sentido, o território a ser explorado não é meramente o ensino de conteúdos que possibilitem a compreensão desse meio, mas, sobretudo o desenvolvimento de práticas, que sendo consolidadas favorece a transformação desse cenário e do próprio sujeito.

A escola para nós hoje é, sem dúvida, uma instituição que tem que ter como eixo norteador a criatividade, a emancipação, a crítica reflexiva, a transformação e a multiplicidade de oportunidades e de eixos estruturantes. Portanto, as relações entre escola e práticas criativas e inovadoras não podem ser concebidas entre dois polos independentes, mas sim como universos entrelaçados, como uma teia tecida no cotidiano com fios e nós profundamente articulados. Assim, construiremos caminhos de aprendizagem com sentidos e significados reesposáveis, sustentáveis e humanizadores.

\section{Referências}

ARROYO, Miguel. Oficio de mestre: imagens e auto-imagem. Petrópolis: Vozes, 2000.

mai. 1988. , Miguel. O direito ao tempo de escola. Cadernos de Pesquisa, n. 65, p. 30- 10,

BARBOSA, Ana Mae. John Dewey e o ensino da arte no Brasil. São Paulo: Cortez, 2002

BRASIL. Ministério da Educação. Lei de Diretrizes e B. Lei no 9.394/96, de 20 de dezembro de 1996. Disponível em: < http://www.planalto.gov.br/ccivil_03/leis/L9394. htm > Acesso em: 28/10/2017.

CORTELLA, M. S. Não espere o Epitáfio - provocações filosóficas. Petrópolis. RJ: Vozes, 2008.

DITTRICH, Maria Gloria. Arte, criatividade, espiritualidade e cura. Blumenau: Nova Letra, 2010.

FERRAZ, Maria Heloisa Correa; FUSARI, Maria Felisminda de Rezende. Arte na educação escolar. São Paulo: Cortez, $4^{a}$ ed. 2010.

FERREIRA, Sueli (org). O ensino das artes: construindo caminhos. Campinas SP: Papirus, 2001.

FREIRE, Paulo. Pedagogia da autonomia. São Paulo: Vozes, 1980. 
LIBÂNEO, José Carlos. A Didática e a Aprendizagem do Pensar e do Aprender: a teoria histórico-cultural da atividade e a contribuição de Vasili Davídov. Revista Brasileira de Educação, Rio de Janeiro, n. 27, p. 5-24, 2004.

LIMONTA, Sandra Valéria. et. al. (Organizadores). Educação integral e Escola Pública de Tempo Integral. Goiânia: Ed. da PUC Goiás, 2013.

LOWENFELD, V. \& BRITTAIN, W.L. Desenvolvimento da capacidade criadora. São Paulo: Mestre Jou, 1977.

OSINSKI, Dulce. Arte, história e ensino - uma trajetória. SP: Cortez, 2001.

PINHO, Maria José de, SUANNO Marilza Vanessa Rosa, SUANNO João Henrique (orgs.). Projetos criativos na prática pedagógica: cantar e encantar a aprendizagem. Goiânia: Editora Espaço Acadêmico, 2015.

RODRIGUES, Maristela Sanches. Desenvolvimento Estético: entre as expectativas do professor e as possibilidades dos alunos. Dissertação - Mestrado: Instituto de Artes da Universidade Estadual Paulista/UNESP. São Paulo, 2008. 252p.

SANTOS; Akiko; SUANNO; João Henrique; SUANNO, Marilza Vanessa Rosa. Didática e formação de professores: complexidade e transdisciplinareidade. Florianópolis: Sulina, 2013.

SAVIANI, Demerval. Educação: do senso comum à consciência filosófica. São Paulo: Cortez, 1989.

TORRE, Saturnino de La. Criatividade Aplicada. SP: Madras, 2008.

VEIGA, Ilma Passos Alencastro. As dimensões do projeto politico-pedagógico. SP: Papirus, 2001. 